\section{Exogenous Application of Abscisic Acid, Putrescine, or 2,4-Epibrassinolide at Appropriate Concentrations Effectively Alleviate Damage to Tomato Seedlings from Suboptimal Temperature Stress}

\author{
Weijie Jiang, Jie Bai, Xueyong Yang, Hongjun $\mathrm{Yu}^{1}$, and \\ Yanpeng Liu
}

\begin{abstract}
ADDITIONAL INDEX wORDs. plant growth regulators, abiotic stresses, vegetable production, Solanum lycopersicum

Summary. The application of plant growth regulators (PGRs), such as abscisic acid (ABA), putrescine (Put), and 2,4-epibrassinolide (EBR), has been shown to enhance a plant's resistance to various abiotic stresses. However, the protective effects of these PGRs on tomato (Solanum lycopersicum) seedlings under suboptimal temperature stress have not yet been evaluated. We also do not know the most effective method of application of PGRs for various tomato cultivars. We studied the effects of three rates of exogenous ABA, Put, or EBR in limiting damage from suboptimal temperature stress on two tomato cultivars, Zhongshu6 (considered sensitive to suboptimal temperatures) and SANTIAM (considered tolerant to suboptimal temperatures). Results showed that application of these PGRs at appropriate concentrations could effectively reduce the decline in the net photosynthetic rate $\left(P_{n}\right)$ and the chlorophyll $(\mathrm{Chl})$ content in leaves caused by suboptimal temperature stress in both 'Zhongshu6' and 'SANTIAM' and could promote an increase in organic osmolyte (proline and soluble sugar) contents and root $2,3,5$ triphenyltetrazolium chloride (TTC)-reducing activity for 'Zhongshu6'. However, these effects were inferior on 'SANTIAM'. For both cultivars, the best treatment concentrations are $1 \mathrm{~mm}$ ABA, $0.1 \mathrm{~mm}$ Put, or $0.02 \mu \mathrm{M}$ EBR. Results indicate that in tomato production, exogenous application of ABA, Put, or EBR at appropriate concentrations can effectively limit damage from suboptimal temperature stress.
\end{abstract}

$\mathrm{T}$ hermophilic fruit vegetables, such as tomato, often suffer from suboptimal temperature stress, which is one of the limiting factors in winter vegetable production in China, leading to a decline in production and quality (Wang et al., 2001). Suboptimal temperatures, which refer to day temperatures less than $20^{\circ} \mathrm{C}$ and night temperatures less than $10^{\circ} \mathrm{C}$, are categorized as a chilling stress, one of the major environmental stresses affecting plant development and performance. Many tropical and subtropical plant species

Institute of Vegetables and Flowers, Chinese Acad-
emy of Agricultural Sciences, Beijing 100081, People's Republic of China

This work was funded by 973 Program (2009CB19001), Ministry of Science and Technology, and supported by the earmarked fund for China Agricultural Research System (CARS-25-C-09), Key Laboratory of Biology and Genetic Improvement of Horticultural Crops, Ministry of Agriculture, People's Republic of China, and National Key Project (2011BAD12B01).

We gratefully acknowledge assistance from Xiaoxuan Wang in supplying tomato seeds.

${ }^{1}$ Corresponding author. E-mail: yuhj@mail.caas.net.cn. are considerably affected when exposed to low temperatures during their life cycles. Many plants can increase their tolerance to freezing temperatures after exposure to a period of nonfreezing temperatures, a phenomenon known as cold acclimation. In the process, plants cope with the low temperatures by employing a number of physiological and cellular changes, including inhibition of plant growth, decrease of photosynthesis and increase of leaf thickness, and increasing osmolytes with cryoprotective properties (such as proline and soluble sugars) and root TTC-reducing activity (Ristic and Ashworth, 1993;
Uemura et al., 1995; Xin and Browse, 2000).

A number of genetic and molecular studies on plant response to low temperatures have resulted in the cloning and characterization of many components of the cold signaling pathway, in which the phytohormone ABA plays an important role (Xin and Browse, 2000). Moreover, Put and another class of phytohormones known as brassinosteroids (BRs) were also shown to be involved in low-temperature response (Cuevas et al., 2008; Kagale et al., 2007).

Abscisic acid is the central regulator of abiotic stress resistance in plants and is involved in many stress responses. A plant's ABA content rapidly accumulates under cold or drought stresses, which helps to stimulate stomatal closure, change gene expression, and increase osmocompatible solutes to improve the plant's capacity to cope with the stress conditions (Cutler et al., 2010; Kim et al., 2010; Seki et al., 2007). In plants, Put is a type of polyamine, a low-molecularmass polycation ubiquitous in all living organisms, and was considered to act as a free radical scavenger to protect the plant from oxidative and chilling stress (Drolet et al., 1986; Galston et al., 1997; Nayyar and Chander, 2004; Shen et al., 2000; Velikova et al., 1998). BRs are a recently classified group of plant hormones that were first isolated from the pollen of rape (Brassica napus) in 1979 (Grove et al., 1979). Research has shown that BRs might be a plasticpromoting hormone that allows a plant to adapt to multiple environmental stresses, such as heavy metals, salt, biotic stress, hypoxia, osmotic stress, and temperature stress (Dhaubhadel et al., 1999; Houimli et al., 2008; Kagale et al., 2007; Kang et al., 2006; Masidur et al., 2007; Nakashita et al., 2003; Vidya and Seeta, 2003).

Studies on the effects of growth regulators on suboptimal temperature stress, which is common in vegetable

\begin{tabular}{llll}
\hline $\begin{array}{l}\text { Units } \\
\text { To convert U.S. to SI, } \\
\text { multiply by }\end{array}$ & U.S. unit & SI unit & $\begin{array}{l}\text { To convert SI to U.S., } \\
\text { multiply by }\end{array}$ \\
\hline 29,574 & $\mathrm{fl} \mathrm{oz}$ & $\mu \mathrm{L}$ & $3.3814 \times 10^{-5}$ \\
29.5735 & $\mathrm{fl} \mathrm{oz}$ & $\mathrm{mL}$ & 0.0338 \\
28.3495 & $\mathrm{Oz}$ & $\mathrm{g}$ & 0.0353 \\
0.001 & $\mathrm{ppm}$ & $\mathrm{mg} \cdot \mathrm{g}^{-1}$ & 1000 \\
1 & $\mathrm{ppm}$ & $\mu \mathrm{\mu g} \cdot \mathrm{g}^{-1}$ & 1 \\
$\left({ }^{\circ} \mathrm{F}-32\right) \div 1.8$ & ${ }^{\circ \mathrm{F}}$ & ${ }^{\circ} \mathrm{C}$ & $\left(1.8 \times{ }^{\circ} \mathrm{C}\right)+32$
\end{tabular}


production, were relatively rare. This study, therefore, investigated what is the induction effect of these exogenous PGRs on tomato seedlings, and whether various chilling-tolerant genotypes of tomato respond differently to these exogenous PGRs. The elucidation of these problems will provide the theoretical basis for understanding the physiological mechanism by which PGRs alleviate the damage in a horticultural crop under chilling stress. It is also important to explore effective ways to apply ABA, Put, or EBR in vegetable production.

\section{Materials and methods}

TOMATO SEEDLING CULTIVATION. Two genotypes of tomato were used in this experiment: chilling-sensitive cultivar Zhongshu6 [Institute of Vegetables and Flowers (IVF), Chinese Academy of Agricultural Sciences (CAAS), Beijing, China] and chillingtolerant cultivar SANTIAM (IVF, CAAS). Tomato seeds were sown in plugs with a mixture of peatmoss and vermiculite $(\mathrm{v} / \mathrm{v}=\mathrm{l}: \mathrm{l})$ as culture substrate. When plants reached three fully expanded leaves, $\mathrm{ABA}(0.2$, $0.6,1 \mathrm{~mm})$, Put $(0.1,0.5,1.0 \mathrm{~mm})$, EBR $(0.01,0.02,0.1 \mu \mathrm{M})$ (Sigma, St. Louis, MO), and water were applied to the foliage of selected uniform seedlings. A second application of the PGR with same concentration was made $5 \mathrm{~d}$ later. Three replications were used for each treatment, and the experimental unit had 15 plants.

Suboptimal temperature TREATMENT. As soon as the fluid sprayed at the second time was no longer visible, and there were no water drops on the leaf surface, the seedlings were divided into two groups, and one group was moved to climatic chambers (PRX-450B; SaiFu, Ningbo, China) at $16 / 8{ }^{\circ} \mathrm{C}$ (day/night) with a light period of $10 \mathrm{~h}$ at a photosynthetic photon flux of $250 \mu \mathrm{mol} \cdot \mathrm{m}^{-2} \cdot \mathrm{s}^{-1}$; the relative humidity was $75 \%$, including the plants sprayed with ABA, Put, EBR, and distilled water. The other group, control samples (CK) including the plants sprayed with distilled water, was then grown in identical climatic chamber kept at $28 / 22^{\circ} \mathrm{C}$ (day/night) under a 10 -h photoperiod with the same conditions described above. Sample collection was carried out on days 0 , $2,4,6$, and 8 of suboptimal temperature stress, including the plants sprayed with distilled water. Three plants were harvested for each sample period.

Photosynthesis measurement. Plant photosynthesis was tested with the second fully expanded leaf under the growing point, on days $0,2,4,6$, and 8 of suboptimal temperature stress, using a portable photosynthesis system (LI-6400; LI-COR, Lincoln, NE) according to the manufacturer's instructions. Three plants were used on each sample period.

CHLOROPHYLL CONTENT MEASUREMENT. The second fully expanded leaf under the growing point was sampled on days $0,2,4,6$, and 8 of suboptimal temperature stress to measure Chl content according to the previous report using an ultraviolet spectrophotometer (ultraviolet-2102PC/
PS; UNICO, Shanghai, China) (Li, 2000 ); three plants were used for each treatment.

Proline and soluble sugar contents measurement. Soluble sugar measurement was carried out according to previous report ( $\mathrm{Li}$ et al., 2004). The second fully expanded leaf were harvested, weighed, and ground to powder in liquid nitrogen and then incubated in $75 \%$ ethanol overnight with gentle shaking. After centrifugation at $20,000 g_{\mathrm{n}}, 20 \mu \mathrm{L}$ of each extract was incubated with $1000 \mu \mathrm{L}$ of anthrone reagents $[0.15 \%(\mathrm{w} / \mathrm{v})$ anthrone, $72 \%(\mathrm{v} / \mathrm{v}) \mathrm{H}_{2} \mathrm{SO}_{4}$, and $28 \%(\mathrm{v} / \mathrm{v})$ water] at $100{ }^{\circ} \mathrm{C}$ for $\mathrm{l} \mathrm{h}$. The soluble sugar value was measured at $630 \mathrm{~nm}$. Proline measurement was carried out according to a previously
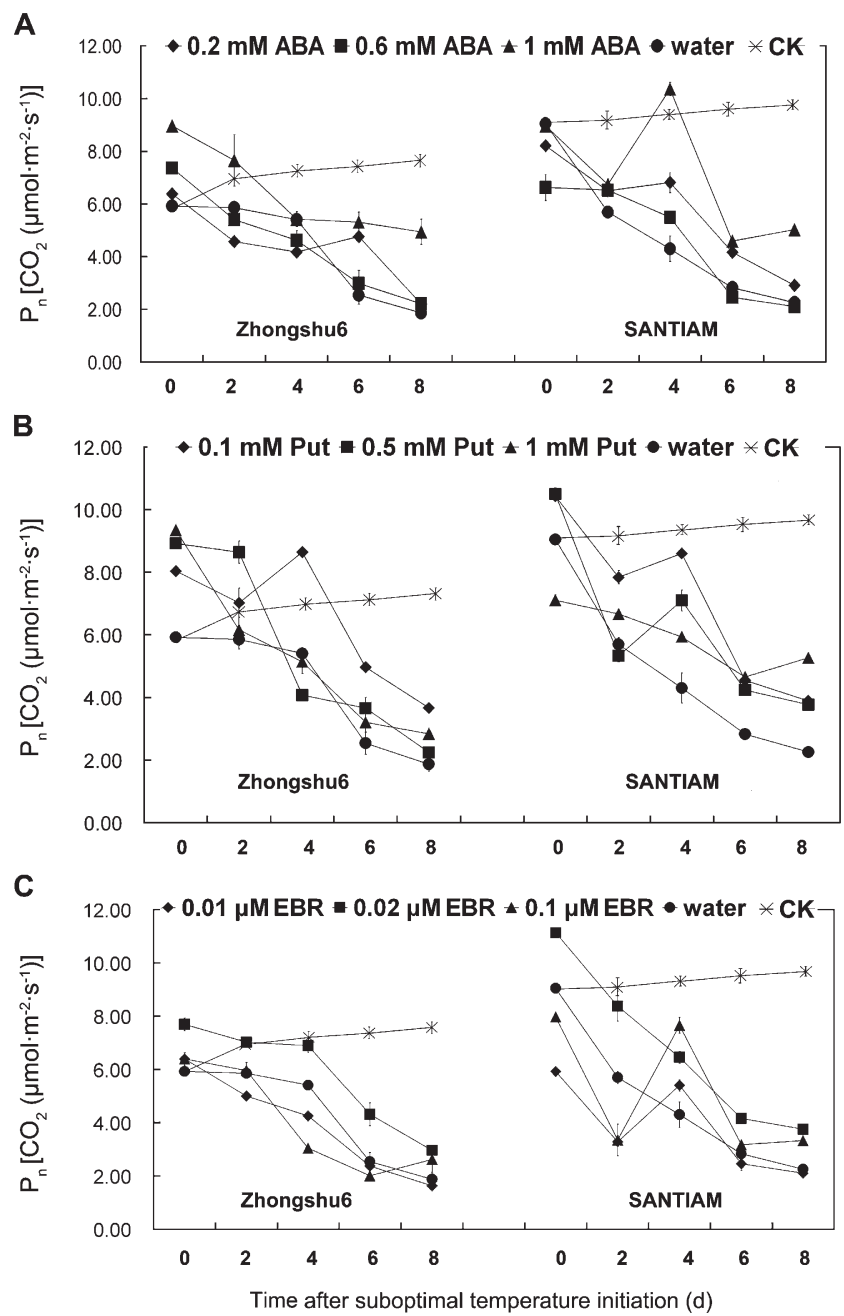

Fig. 1. The effects of exogenous (A) abscisic acid (ABA), (B) putrescine (Put), and (C) 2,4-epibrassinolide (EBR) on leaf net photosynthetic rate $\left(P_{n}\right)$ of the chillingsensitive tomato cultivar Zhongshu6 and the chilling-tolerant cultivar SANTIAM under suboptimal temperature stress. Water $=$ control samples sprayed with distilled water and grown at $16 / 8{ }^{\circ} \mathrm{C}\left(60.8 / 46.4^{\circ} \mathrm{F}\right)($ day/night $)$ and $\mathrm{CK}=$ control samples sprayed with distilled water and grown at $28 / 22{ }^{\circ} \mathrm{C}\left(82.4 / 71.6^{\circ} \mathrm{F}\right)($ day/night $)$. Each value is the mean of three replications, and the vertical bars indicate $\operatorname{SD}(n=3)$. 
described method (Bates et al., 1973). The second fully expanded leaf were weighed and subjected to extraction using 3\% sulfosalicylic acid. After filtration, $2 \mathrm{~mL}$ of each filtrate was incubated with $2 \mathrm{~mL}$ of glacial acetic acid and $2 \mathrm{~mL}$ of acid ninhydrin reagent [2.5\% $(\mathrm{w} / \mathrm{v})$ ninhydrin, $60 \%(\mathrm{v} / \mathrm{v})$ glacial acetic acid, and $40 \%(\mathrm{v} / \mathrm{v}) 6 \mathrm{M}$ phosphoric acid] at $100^{\circ} \mathrm{C}$ for $\mathrm{l} \mathrm{h}$. The reaction was ended in an ice bath. Toluene $(4 \mathrm{~mL})$ was added into the extractions followed by vigorous shaking for $20 \mathrm{~s}$. After incubation at $23^{\circ} \mathrm{C}$ for $24 \mathrm{~h}$, the proline values were measured at $520 \mathrm{~nm}$.

Root ACTIVITY MEASUREMENT. Measurement of root activity was performed according to the TTC method (Wang et al., 2010a). The substrate was removed from the root using tweezers, and then the roots were washed with sterile water. The surface liquid of roots was blotted with tissue paper and their fresh weights were measured. Roots with weights $0.5 \mathrm{~g}$ were placed in tubes and filled with $5 \mathrm{~mL}$ of $0.4 \%$ TTC and $5 \mathrm{~mL}$ phosphate buffer $\left(0.06 \mathrm{~mol} \cdot \mathrm{L}^{-1}, \mathrm{pH}\right.$ 7.0). Control treatment (blank runs) was always carried out using the same procedure, but adding $2 \mathrm{~mL}$ of 1 $\mathrm{mol} \cdot \mathrm{L}^{-1}$ sulfuric acid first. The tubes were incubated at $37^{\circ} \mathrm{C}$ for up to $4 \mathrm{~h}$. The chemical reaction was stopped by adding $2 \mathrm{~mL}$ of $1 \mathrm{~mol} \cdot \mathrm{L}^{-1}$ sulfuric acid into the tubes. This step was followed by extraction with $10 \mathrm{~mL}$ of $95 \%$ ethanol for $24 \mathrm{~h}$, which consisted of taking the root in a new tube. The optical density values were recorded at $485 \mathrm{~nm}$.

Statistical analyses. Each of the five physiological indices was analyzed using Proc Mixed in SAS (version 8.0; SAS Institute, Cary, NC) with a variance-covariance structure for the repeated measures analysis of variance. The variance-covariance structure was determined to be compound symmetry structure, and the interactions between treatments and days were significant. Then the treatment comparisons within each day were made. The results presented in the table of each column were the mean of three replications, and means were compared with Duncan's multiple range test $(P<0.05)$ analyzed by SAS (version 8.0).

\section{Results}

The EFFeCTS OF PGRs ON LEAF NET PHOTOSYNTHETIC RATE UNDER
SUBOPTIMAL TEMPERATURE STRESS. As shown in Fig. 1, under normal conditions (day 0 ), the leaf $P_{n}$ of 'SANTIAM' $\left(8.2 \mu \mathrm{mol} \cdot \mathrm{m}^{-2} \cdot \mathrm{s}^{-1} \mathrm{CO}_{2}\right)$ was higher than that of 'Zhongshu6' $\left(6.4 \mu \mathrm{mol} \cdot \mathrm{m}^{-2} \cdot \mathrm{s}^{-1} \mathrm{CO}_{2}\right)$. When suffering from suboptimal temperature stress, the leaf $P_{n}$ of 'SANTIAM' significantly decreased immediately, whereas that of 'Zhongshu6' decreased after the fourth day (Fig. 1). However, exogenous ABA, Put, or EBR applied at appropriate concentrations effectively reduced the decrease in $P_{n}$ under suboptimal temperature stress (Fig. 1A-C). As shown in Fig. lA, during the days of stress, only I mM ABA significantly reduced the decline in $\mathrm{P}_{\mathrm{n}}$ of 'Zhongshu6' and maintained $P_{n}$ levels that were remarkably higher than those found in the watertreated plants by $51.2 \%, 30.8 \%$, $109.0 \%$, and $164.0 \%$ on days 0,2 , 6 , and 8 , respectively. For the suboptimal temperature-tolerant cultivar SANTIAM, only $0.6 \mathrm{~mm} \mathrm{ABA}$ did not show any response, whereas $1 \mathrm{~mm}$ provided the greatest effect, with $\mathrm{P}_{\mathrm{n}}$ levels higher than those found in the water-treated plants by $18.3 \%$, $141.0 \%, 62.2 \%$, and $123.0 \%$ on days $2,4,6$, and 8 of stress, respectively.

Table 1. Effects of abscisic acid (ABA), putrescine (Put), and 2,4-epibrassinolide (EBR) on net photosynthetic rate $\left(P_{n}\right)$, leaf chlorophyll content $(\mathrm{Chl})$, proline content, sugar content, and root activity of chilling-sensitive ('Zhongshu6') and chillingtolerant ('SANTIAM') tomato cultivars on the day 8 of suboptimal temperature. The results presented in each column are the means of three replications.

\begin{tabular}{|c|c|c|c|c|c|c|c|}
\hline \multirow{2}{*}{$\frac{\text { Cultivar }}{\text { Zhongshu6 }}$} & \multicolumn{2}{|c|}{ Treatment $\mathrm{t}^{\mathrm{z}}$} & \multirow{2}{*}{$\begin{array}{c}\mathbf{P}_{\mathrm{n}} \\
{\left[\mathrm{CO}_{2}\left(\mu \mathrm{mol} \cdot \mathbf{m}^{-2} \cdot \mathbf{s}^{-1}\right)\right]} \\
2.21 \mathrm{e}^{\mathrm{x}}\end{array}$} & \multirow{2}{*}{$\begin{array}{c}\begin{array}{c}\text { Chl content } \\
\left(\mathrm{mg} \cdot \mathrm{g}^{-1} \mathrm{FW}\right)^{\mathrm{y}}\end{array} \\
0.89 \mathrm{i}\end{array}$} & \multirow{2}{*}{$\begin{array}{c}\begin{array}{c}\text { Proline content } \\
(\mu \mathrm{g} \cdot \mathrm{g}-1 \mathrm{FW})^{\mathrm{y}}\end{array} \\
95.29 \mathrm{c}\end{array}$} & \multirow{2}{*}{$\begin{array}{c}\begin{array}{c}\text { Sugar } \\
\text { content }(\%)\end{array} \\
2.85 \mathrm{~cd}\end{array}$} & \multirow{2}{*}{$\begin{array}{c}\begin{array}{c}\text { Root activity } \\
\left(\mu \mathrm{g} \cdot \mathrm{g}^{-1} \mathrm{FW} \text { per hour }\right)\end{array} \\
1324.96 \mathrm{~cd}\end{array}$} \\
\hline & $\mathrm{ABA}$ & $0.2 \mathrm{~mm}$ & & & & & \\
\hline & & $0.6 \mathrm{mM}$ & $2.22 \mathrm{e}$ & $1.37 \mathrm{c}$ & $105.05 \mathrm{bc}$ & $3.14 \mathrm{bc}$ & $1729.99 \mathrm{ab}$ \\
\hline & & $1 \mathrm{~mm}$ & $4.94 \mathrm{a}$ & $1.51 \mathrm{a}$ & $113.58 \mathrm{ab}$ & $3.40 \mathrm{~b}$ & $1913.72 \mathrm{a}$ \\
\hline & Put & $0.1 \mathrm{~mm}$ & $3.67 \mathrm{~b}$ & $1.39 \mathrm{~b}$ & $114.99 \mathrm{ab}$ & $3.44 \mathrm{~b}$ & $1783.43 \mathrm{a}$ \\
\hline & & $0.5 \mathrm{~mm}$ & $2.24 \mathrm{e}$ & $1.19 \mathrm{f}$ & 97.89 bc & $2.93 \mathrm{c}$ & $1006.80 \mathrm{de}$ \\
\hline & & $0.02 \mu \mathrm{M}$ & $2.96 \mathrm{c}$ & $1.27 \mathrm{~d}$ & $129.13 \mathrm{a}$ & $3.86 \mathrm{a}$ & $1696.68 \mathrm{abc}$ \\
\hline & & $0.1 \mu \mathrm{M}$ & $2.61 \mathrm{~d}$ & $1.24 \mathrm{e}$ & $102.58 \mathrm{bc}$ & $3.07 \mathrm{bc}$ & $1681.95 \mathrm{abc}$ \\
\hline & & Vater & $1.87 \mathrm{f}$ & $1.09 \mathrm{~g}$ & $101.81 \mathrm{bc}$ & $2.44 \mathrm{~d}$ & $1199.63 \mathrm{de}$ \\
\hline \multirow[t]{7}{*}{ SANTIAM } & $\mathrm{ABA}$ & $0.2 \mathrm{~mm}$ & $2.91 \mathrm{e}$ & $1.17 \mathrm{c}$ & $103.73 \mathrm{ab}$ & $3.10 \mathrm{ab}$ & $1548.85 \mathrm{~d}$ \\
\hline & & $0.6 \mathrm{mM}$ & $2.11 \mathrm{f}$ & $1.22 \mathrm{bc}$ & $95.38 \mathrm{bc}$ & $2.85 \mathrm{bc}$ & $1309.79 \mathrm{~g}$ \\
\hline & & $1 \mathrm{~mm}$ & $5.26 \mathrm{a}$ & $0.98 \mathrm{~d}$ & $103.07 \mathrm{abc}$ & $3.08 \mathrm{abc}$ & $1535.28 \mathrm{e}$ \\
\hline & EBR & $0.01 \mu \mathrm{M}$ & $2.10 \mathrm{f}$ & $1.15 \mathrm{c}$ & $111.23 \mathrm{a}$ & $3.33 \mathrm{a}$ & $1158.33 \mathrm{~h}$ \\
\hline & & $0.02 \mu \mathrm{M}$ & $3.75 \mathrm{c}$ & $1.19 \mathrm{bc}$ & $97.49 \mathrm{abc}$ & $2.92 \mathrm{abc}$ & $1710.54 \mathrm{~b}$ \\
\hline & & $0.1 \mu \mathrm{M}$ & $3.32 \mathrm{~d}$ & $1.17 \mathrm{c}$ & $102.40 \mathrm{abc}$ & $3.07 \mathrm{abc}$ & $826.25 \mathrm{i}$ \\
\hline & & Vater & $2.26 \mathrm{f}$ & $1.20 \mathrm{bc}$ & $104.98 \mathrm{ab}$ & $3.11 \mathrm{ab}$ & $1311.93 \mathrm{~g}$ \\
\hline
\end{tabular}

${ }^{\mathrm{z}}$ Water $=$ control samples sprayed with distilled water grown at $16 / 8^{\circ} \mathrm{C}\left(60.8 / 46.4{ }^{\circ} \mathrm{F}\right)($ day $/$ night $)$.

${ }^{y} \mathrm{l} \mathrm{mg} \cdot \mathrm{g}^{-1}=1000 \mathrm{ppm}, 1 \mu \mathrm{g} \cdot \mathrm{g}^{-1}=1 \mathrm{ppm}, \mathrm{FW}=$ fresh weight.

${ }^{x}$ For each tomato cultivar, means within a column followed by the same letter are not significantly different via Duncan's multiple range test at $P<0.05$. 
Figure $1 \mathrm{~B}$ shows that $0.1,0.5$, and $1 \mathrm{~mm}$ concentrations of Put could reduce the decrease in $P_{n}$ in the two cultivars to varying degrees, and $0.1 \mathrm{~mm}$ Put showed the most significant effect on Zhongshu6, the $P_{n}$ of which was effectively increased by $96.3 \%$ on day 8 of stress compared with that of water-treated plants (Table 1 ). The effect of exogenous application of Put on 'SANTIAM' was more effective than it was on 'Zhongshu6'. On day 8 of stress, the $P_{n}$ of 'SANTIAM' plant treated with $0.1,0.5$, and $1 \mathrm{~mm}$ Put was higher than that of the watertreated plants by $72.0 \%, 67.0 \%$, and $133.0 \%$, respectively (Table 1 ).

Figure $1 \mathrm{C}$ indicates that among the three concentrations, only $0.02 \mu \mathrm{M}$ EBR (Fig. 1C) revealed a prominent effect on both 'Zhongshu6' and 'SANTIAM'. Compared with the water-treated plants, the $\mathrm{P}_{\mathrm{n}}$ of the treated 'Zhongshu6' increased by $30 \%$, $20 \%, 28 \%, 70 \%$, and $58 \%$, and the $\mathrm{P}_{\mathrm{n}}$ of the treated 'SANTIAM' increased by $23 \%, 47 \%, 50 \%, 47 \%$, and $66 \%$ on days $0,2,4,6$, and 8 of stress, respectively.

The effects of the three concentrations of ABA, Put, or EBR on the leaf $\mathrm{P}_{\mathrm{n}}$ on day 8 of suboptimal temperature were compared. The results showed that for 'Zhongshu6', $1 \mathrm{~mm}$ ABA had the greatest effect $\left(P_{n}\right.$ increased by $164.0 \%$ ) and for 'SANTIAM', $1 \mathrm{~mm}$ $\mathrm{ABA}$ and $\mathrm{l} \mathrm{mm}$ Put had almost the same best effect $\left(P_{n}\right.$ increased by $123.0 \%$ and $133.0 \%$, respectively) (Table 1).

The effects of PGRs on CHLOROPHYLL CONTENT UNDER SUBOPTIMAL TEMPERATURE STRESS. As shown in Fig. 2, the Chl content of 'SANTIAM' [1.6 mg. $\mathrm{g}^{-1}$ fresh weight $(\mathrm{FW})$ ] was higher than that of 'Zhongshu6' (1.4 mg. ${ }^{-1} \mathrm{FW}$ ) under normal conditions. During chilling stress, the Chl content of 'Zhongshu6' appeared more stable than that of 'SANTIAM' before day 6 but decreased more dramatically later. For 'Zhongshu6', except for $0.2 \mathrm{~mm} \mathrm{ABA}$ and $1 \mathrm{~mm}$ Put, all the treatments reduced the decline in the $\mathrm{Chl}$ content under suboptimal temperatures, and similar to the results above, treatments with $1 \mathrm{~mm} \mathrm{ABA}, 0.1 \mathrm{~mm}$ Put, and 0.02 $\mu \mathrm{M}$ EBR produced the greatest induced effect (Fig. 2A-C), with the Chl content higher on day 8 than that of the water-treated plants by $37.9 \%$, $27.3 \%$, and $15.6 \%$, respectively (Table 1). For 'SANTIAM', the Chl content

A

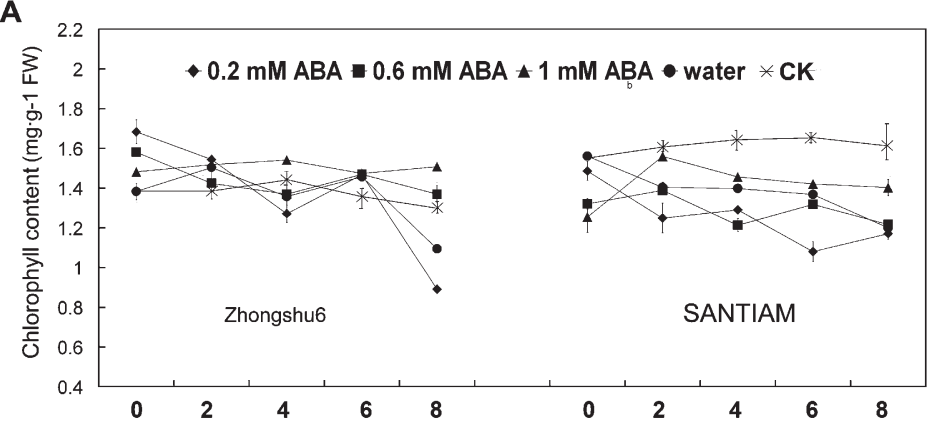

B

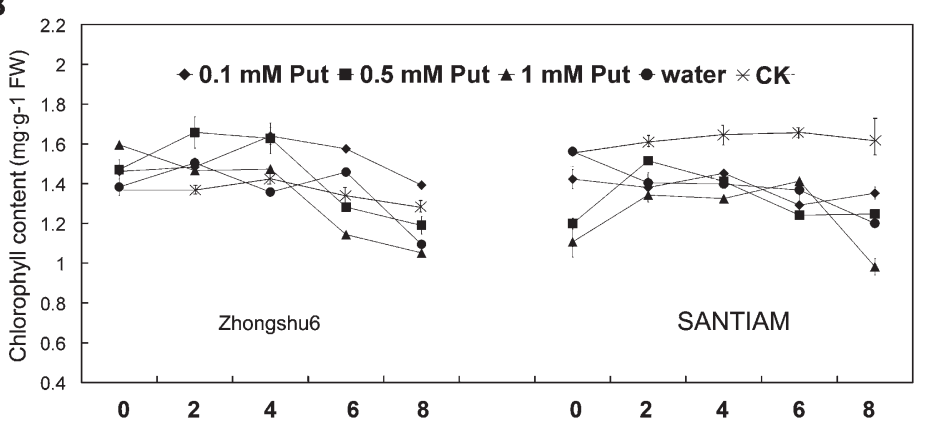

C

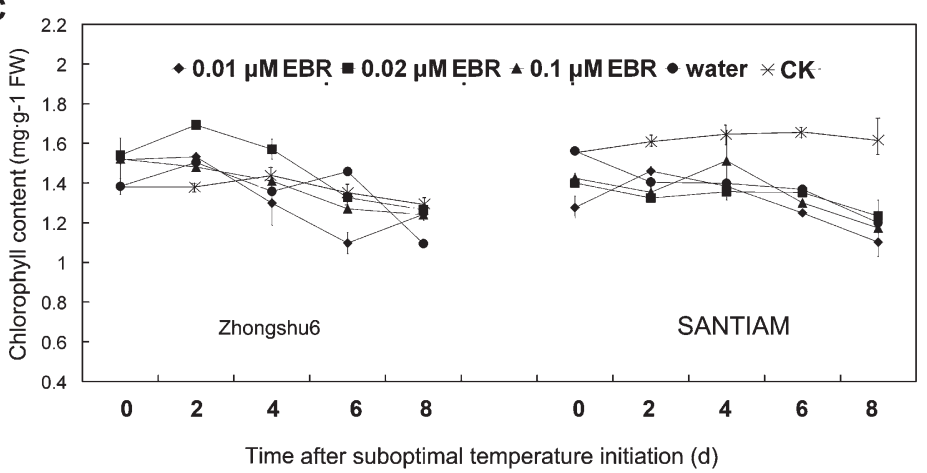

Fig. 2. The effects of exogenous (A) abscisic acid (ABA), (B) putrescine (Put), and (C) 2,4-epibrassinolide (EBR) on the chlorophyll content of the chilling-sensitive tomato cultivar Zhongshu6 and the chilling-tolerant cultivar SANTIAM under suboptimal temperature stress. Water $=$ control samples sprayed with distilled water grown at $16 / 8^{\circ} \mathrm{C}\left(60.8 / 46.4{ }^{\circ} \mathrm{F}\right)($ day/night $), \mathrm{CK}=$ control samples sprayed with distilled water grown at $28 / 22^{\circ} \mathrm{C}\left(82.4 / 71.6^{\circ} \mathrm{F}\right)$ (day/night), and $\mathrm{FW}=$ fresh weight. Each value is the mean of three replications, and the vertical bars indicate SD $(n=3) ; 1 \mathrm{mg} \cdot \mathrm{g}^{-1}=1000 \mathrm{ppm}$.

was relatively more stable when treated with the exogenous PGRs under suboptimal temperatures; however, the treatments with $1 \mathrm{~mm} \mathrm{ABA}$ or 0.1 $\mathrm{mm}$ Put had a remarkable effect on the increase of Chl content (Fig. 2AC), which increased on day 8 by $16.9 \%$ and $12.7 \%$, respectively ( $\mathrm{Ta}$ ble 1). Interestingly, the treatments with the three concentrations of EBR were not effective for 'SANTIAM'. Results indicate that an appropriate concentration of ABA, Put, or EBR can reduce the decline in $\mathrm{Chl}$ content and that the induced effect was more obvious on 'Zhongshu6' than on 'SANTIAM'.
Comparing the effects of $\mathrm{ABA}$, Put, and EBR treatments on reducing the decline of Chl content on day 8 due to low temperature, we found that $1 \mathrm{~mm} A B A$ was the best choice for both 'Zhongshu6' and 'SANTIAM' [Chl content increased by $37.9 \%$ and $16.9 \%$, respectively (Table 1)].

The efFects of PGRs on the PROLINE CONTENT UNDER SUBOPTIMAL TEMPERATURE STRESS. Results showed that under normal conditions (day 0 ), the proline content of 'SANTIAM' $\left(40.5 \mu \mathrm{g} \cdot \mathrm{g}^{-1} \mathrm{FW}\right)$ was lower than that of 'Zhongshu6' (47.8 $\mu \mathrm{g} \cdot \mathrm{g}^{-1} \mathrm{FW}$ ). During the period of suboptimal temperature stress, the proline content of 
both cultivars increased; however, that of SANTIAM increased more rapidly, which might be one of the reasons why 'SANTIAM' is more tolerant to chilling. When treated with ABA, Put, or EBR, the proline content of 'Zhongshu6' increased equally during the period of stress, whereas that of 'SANTIAM' reached a maximum on day 6 and then decreased (Fig. 3).

As shown in Fig. 3, exogenous $\mathrm{ABA}$, Put, or EBR applied at $1 \mathrm{~mm}$, $0.1 \mathrm{mM}$, and $0.02 \mu \mathrm{M}$ could significantly improve the proline content of 'Zhongshu6'. Among the three PGRs, $1 \mathrm{~mm}$ ABA had the greatest effect on 'Zhongshu6', producing a proline content higher than that of the water-treated plants by $37.1 \%$, $112 \%, 53.3 \%, 17.3 \%$, and $11.6 \%$ on days $0,2,4,6$, and 8 , respectively. When treated with $0.1 \mathrm{~mm}$ Put or $0.02 \mu \mathrm{M} \mathrm{EBR}$, the proline content of 'Zhongshu6' increased by $0 \%, 59.0 \%$, $34.8 \%, 36.0 \%$, and $12.9 \%$ or by $7.6 \%$, $75.6 \%, 42.3 \%, 24.2 \%$, and $26.8 \%$, respectively, on days $0,2,4,6$, and 8 , respectively (Fig. 3A-C). However, none of the concentrations of these PGRs had any significant effect on promoting the proline content of 'SANTIAM' under suboptimal temperature, except on day 6 of stress, when $1 \mathrm{~mm}$ ABA, $0.1 \mathrm{~mm}$ Put, and $0.02 \mu \mathrm{M}$ EBR significantly increased the proline content by $51.1 \%$, $14.4 \%$, and $22.2 \%$, respectively (Fig. $3 \mathrm{~A}-\mathrm{C})$.

The results showed that among these treatments, $1 \mathrm{~mm}$ ABA had the greatest effect on both 'Zhongshu6' and 'SANTIAM' for increasing the proline content to resist suboptimal temperature stress (Table 1 ).

The efFects of PGRs on SOLUBLE SUGAR UNDER SUBOPTIMAL TEMPERATURE STRESS. As shown in Fig. 4, the soluble sugar content of 'Zhongshu6' increased gradually over time under suboptimal temperature stress, whereas that of 'SANTIAM' increased quickly, reached a maximum on day 6 , and then decreased. The exogenous ABA, Put, or EBR increased the soluble sugar content even further and maintained the higher level at later stages of stress. Similarly, treatments with $1 \mathrm{~mm} \mathrm{ABA}, 0.1 \mathrm{~mm}$ Put, and $0.02 \mu \mathrm{M}$ EBR produced a significant induced effect on 'Zhongshu6', increasing the sugar content on day 8 over that of the water-treated plants by $47.7 \%, 49.5 \%$, and $67.9 \%$,

A

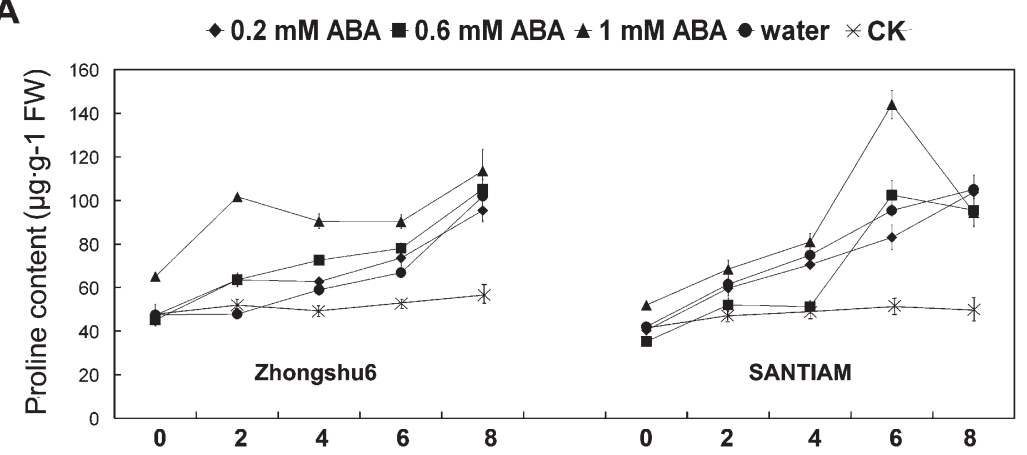

B

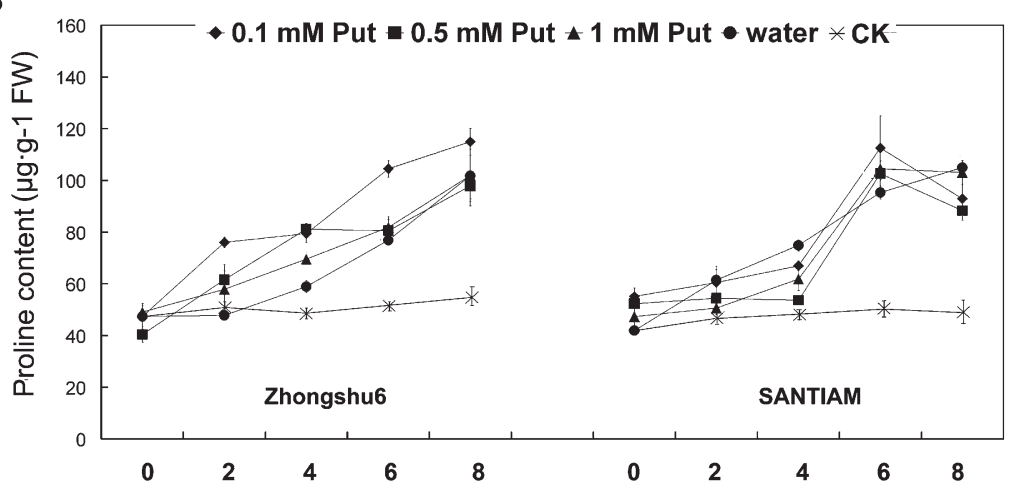

C

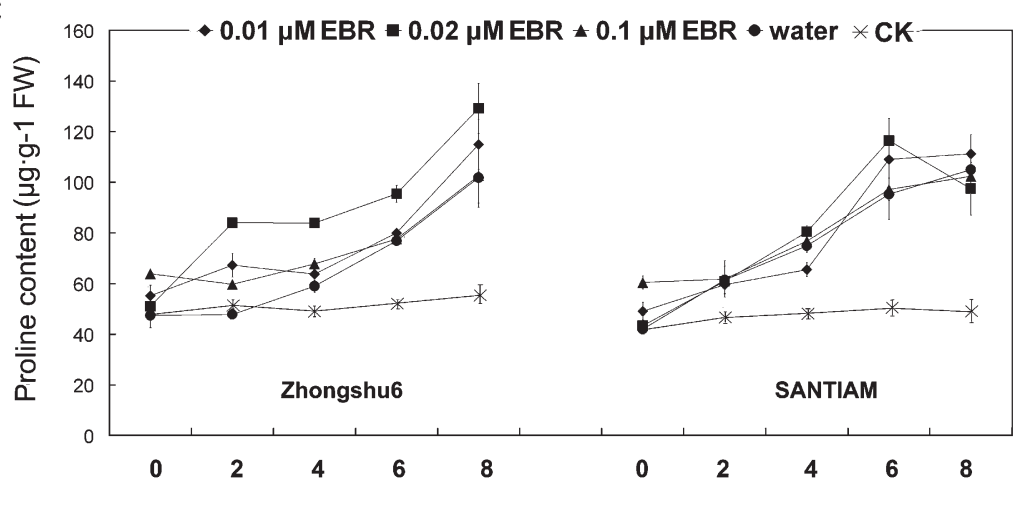

Time after suboptimal temperature initiation (d)

Fig. 3. The effects of exogenous (A) abscisic acid (ABA), (B) putrescine (Put), and (C) 2,4-epibrassinolide (EBR) on the proline content of the chilling-sensitive tomato cultivar Zhongshu6 and the chilling-tolerant cultivar SANTIAM under suboptimal temperature stress. Water $=$ control samples sprayed with distilled water grown at $16 / 8^{\circ} \mathrm{C}\left(60.8 / 46.4{ }^{\circ} \mathrm{F}\right)($ day/night $), \mathrm{CK}=$ control samples sprayed with distilled water grown at $28 / 22{ }^{\circ} \mathrm{C}\left(82.4 / 71.6{ }^{\circ} \mathrm{F}\right)$ (day/night), and $\mathrm{FW}=$ fresh weight. Each value is the mean of three replications, and the vertical bars indicate SD $(n=3) ; 1 \mu \mathrm{g} \cdot \mathrm{g}^{-1}=1 \mathrm{ppm}$.

respectively (Table 1 ). Similar to the results with the proline content, the PGRs here produced inferior effects on 'SANTIAM' in increasing soluble sugar content. Except for $1 \mathrm{~mm} \mathrm{ABA \text {, }}$ which increased the soluble sugar content of 'SANTIAM' by $23.6 \%, 11.3 \%$, $20.8 \%$, and $24.9 \%$ on days $0,2,4$, and 6 , respectively (Fig. 4), no treatment had a significant effect in promoting the soluble sugar content of the chillingtolerant cultivar SANTIAM.
The effects of PGRs on root $2,3,5$ - TRIPHENYLTETRAZOLIUM CHLORIDE-REDUCING ACTIVITY UNDER SUBOPTIMAL TEMPERATURE STRESS. AS shown in Fig. 5, under normal conditions (day 0), the root TTC-reducing activity in 'Zhongshu6' was similar to that of 'SANTIAM'. Under suboptimal temperature stress, for all the treatments, the root TTC-reducing activities of the two cultivars first increased, reached a maximum on day 6 , 

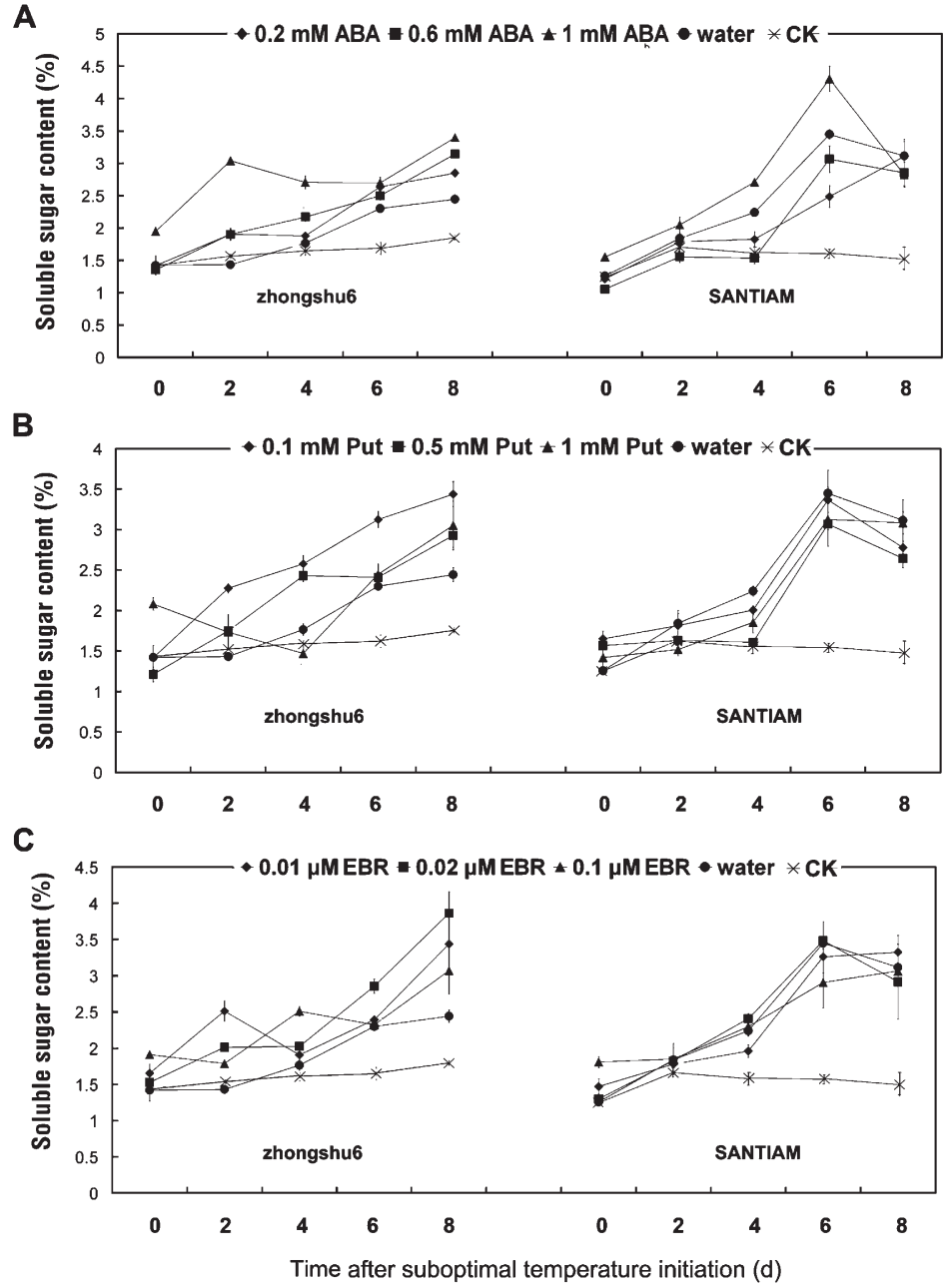

Fig. 4. The effects of exogenous (A) abscisic acid (ABA), (B) putrescine (Put), and (C) 2,4-epibrassinolide (EBR) on the soluble sugar content of the chilling-sensitive tomato cultivar Zhongshu6 and the chilling-tolerant cultivar SANTIAM under suboptimal temperature stress. Water = control samples sprayed with distilled water grown at $16 / 8^{\circ} \mathrm{C}\left(60.8 / 46.4{ }^{\circ} \mathrm{F}\right)(\mathrm{day} /$ night $)$ and $\mathrm{CK}=$ control samples sprayed with distilled water grown at $28 / 22{ }^{\circ} \mathrm{C}\left(82.4 / 71.6{ }^{\circ} \mathrm{F}\right)($ day/night $)$. Each value is the mean of three replications, and the vertical bars indicate $\mathrm{SD}(n=3)$.

and then decreased; however, the activities in 'SANTIAM' reached a higher peak value than that of 'Zhongshu6', which also might be one of the reasons why 'SANTIAM' is more chilling tolerant. We inferred that under suboptimal temperatures, to maintain a normal nutrition metabolism and improve the absorption of inorganic ions to resist damage, the root TTC-reducing activity can increase compensatively. Similarly, exogenous $\mathrm{ABA}$, Put, or EBR treatments applied at the proper concentrations could further increase root TTC-reducing activity in 'Zhongshu6', in which treatments with $1 \mathrm{~mm} \mathrm{ABA}$, $0.1 \mathrm{~mm}$ Put, and $0.02 \mu \mathrm{M}$ EBR showed the greatest effect in improving the root activities, and were higher on day 8 than that of the water-treated plants by $59.5 \%, 48.7 \%$, and $41.4 \%$, respectively (Fig. 5). For 'SANTIAM', we observed that only $1 \mathrm{~mm} \mathrm{ABA}, 0.1 \mathrm{~mm}$ Put, and $0.02 \mu \mathrm{M}$ EBR could significantly increase the root TTC-reducing activities, which were higher on day 8 than that of the water-treated plants by $31.5 \%, 23.9 \%$, and $30.4 \%$, respectively (Table 1$)$. The results indicated that foliar spraying of $1 \mathrm{~mm} \mathrm{ABA}, 0.1 \mathrm{~mm}$ Put, or $0.02 \mu \mathrm{M}$ EBR had a significant effect in increasing root TTC-reducing activities under suboptimal temperature on both 'Zhongshu6' and 'SANTIAM', and $1 \mathrm{mM} A B A$ was more effective than the other two (Table 1 ).

\section{Discussion}

The structure and function of cell membranes do not suffer damage under suboptimal temperature conditions as they do in extreme coldness (van de Dijk and Smeets, 1984); however, suboptimal temperatures can decrease photosynthesis and increase the presence of osmolytes with cryoprotective properties (such as proline and soluble sugars) and root TTC-reducing activity. We have previously reported that exogenous EBR could enhance plant tolerance to weak light (Wang et al., 2010b). Here, we demonstrated that in tomato production, exogenous $\mathrm{ABA}$, Put, or EBR applied in advance at appropriate concentrations can effectively alleviate the damage from suboptimal temperatures.

Previous studies showed that suboptimal temperature stress was not harmful to the structure and function of chloroplasts but could suppress the transport of photosynthate, which ultimately results in a decline in the photosynthetic rate. At the same time, the cold signaling pathway and related genes will be activated to adopt a series of adaptive responses, such as the increase of proline, soluble sugar, and root TTC-reducing activity that increase the osmotic pressure on the plant cells and limit damage from suboptimal temperature stress. During the last decade, many studies on the application of exogenous ABA, Put, or EBR showed these compounds can enhance plant resistance to various abiotic stresses (Dhaubhadel et al., 1999; Hwang and VanToai, 1991; Krishnamurthy, 1991; Masidur et al., 2007; Pospísilová and Bat'ková, 2004; Rajasekaran and Blake, 1999; Vidya and Seeta, 2003; Wang et al., 2010b). In our current study, the results showed that under suboptimal temperature stress, exogenous ABA, Put, or EBR treatments, especially at $1 \mathrm{~mm}$, $0.1 \mathrm{~mm}$, or $0.02 \mu \mathrm{M}$, respectively, can effectively reduce the decline in $P_{n}$ and Chl content and increase the proline and soluble sugar content and the root TTC-reducing activity of the chilling-sensitive tomato cultivar Zhongshu6 and that the induction effect of $1 \mathrm{~mm} A B A$ was the greatest among the three PGRs (Figs. 1-5). Interestingly, we observed that although exogenous ABA, Put, or EBR could significantly alleviated damage from suboptimal temperature stress for the chilling-tolerant tomato cultivar SANTIAM, the induction effects of these PGRs were 


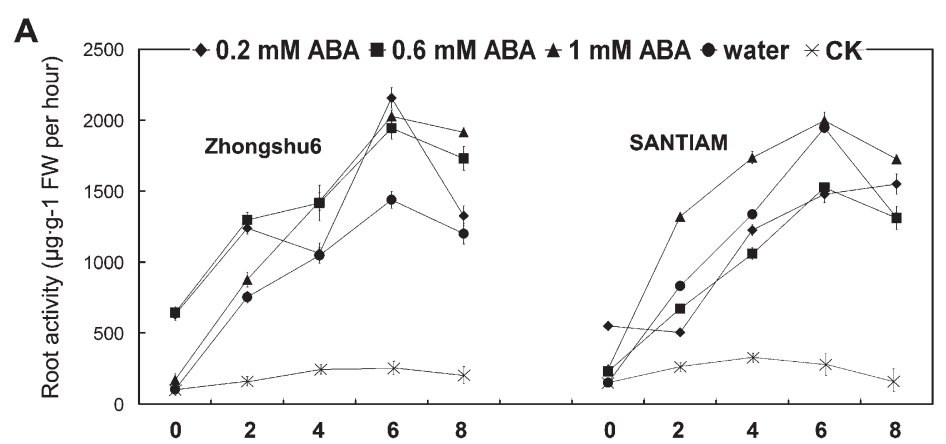

B

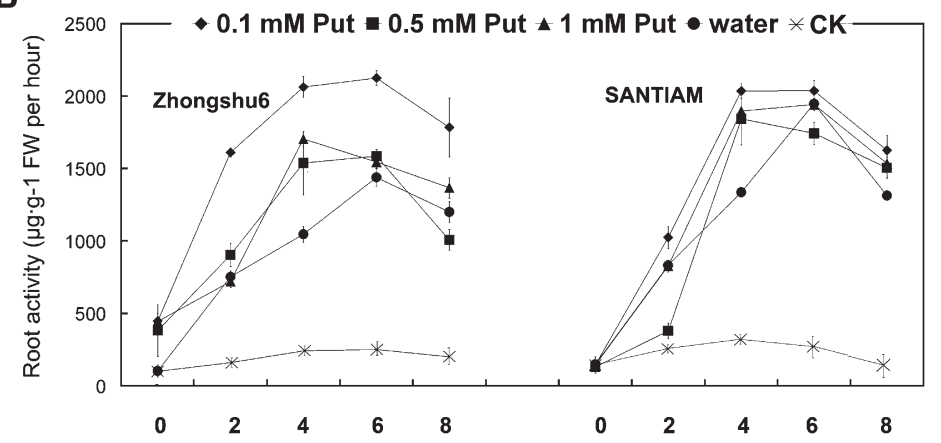

C

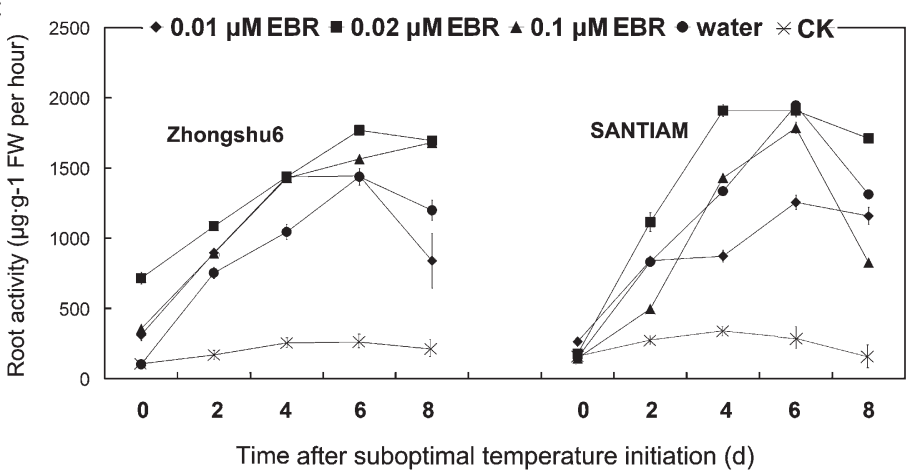

Fig. 5. The effects of exogenous (A) abscisic acid (ABA), (B) putrescine (Put), and (C) 2,4-epibrassinolide (EBR) on the root activity of the chilling-sensitive tomato cultivar Zhongshu6 and the chilling-tolerant cultivar SANTIAM under suboptimal temperature stress. Water $=$ control samples sprayed with distilled water grown at $16 / 8{ }^{\circ} \mathrm{C}\left(60.8 / 46.4^{\circ} \mathrm{F}\right)($ day/night $), \mathrm{CK}=$ control samples sprayed with distilled water grown at $28 / 22^{\circ} \mathrm{C}\left(82.4 / 71.6^{\circ} \mathrm{F}\right)$ (day/night), and $\mathrm{FW}=$ fresh weight. $\mathrm{Each}$ value is the mean of three replications, and the vertical bars indicate $\mathrm{SD}(n=3)$; 1 $\mu \mathrm{g} \cdot \mathrm{g}^{-1}=1 \mathrm{ppm}$.

poorer than that found in 'Zhongshu6' (Figs. 1-5).

Comparing the physiological changes in 'Zhongsu6', our results indicate that during chilling stress, the soluble sugar content, proline content, and root TTC-reducing activities of 'SANTIAM' increased quickly and then reached high peak values; however the leaf $P_{n}$ in 'SANTIAM' decreased quickly, whereas its Chl content was more stable (Figs. 1-5). We inferred that for the chilling-tolerant cultivar SANTIAM, a cellular cold signaling pathway might be highly activated and can produce quick increase in
$\mathrm{mM})$, or $\operatorname{EBR}(0.02 \mu \mathrm{M})$ produces a remarkable effect in both the chillingsensitive cultivar Zhongshu6 and the chilling-tolerant cultivar SANTIAM to reduce the decrease in the $P_{n}$ and Chl content and further increase the proline content, soluble sugar content, and root TTC-reducing activity in tomato seedlings under suboptimal temperature stress.

\section{Literature cited}

Bates, L.S., R.P. Waldren, and I.D. Teare. 1973. Rapid determination of free proline for water-stress studies. Plant Soil 39:205-207.

Cuevas, J.C., R. Lo'pez-Cobollo, R. Alca'zar, X. Zarza, C. Koncz, T. Altabella, J. Salinas, A.F. Tiburcio, and A. Ferrando. 2008. Putrescine is involved in Arabidopsis freezing tolerance and cold acclimation by regulating abscisic acid levels in response to low temperature. Plant Physiol. 148:1094-1105.

Cutler, S.R., P.L. Rodriguez, R.R. Finkelstein, and S.R. Abrams. 2010. Abscisic acid: Emergence of a core signaling network. Annu. Rev. Plant Biol. 61: 651-679.

Dhaubhadel, S., S. Chaudhary, K. Dobinson, and P. Krishna. 1999. Treatment with 24epibrassinolide, a brassinosteroid, increases the basic thermotolerance of Brassica napus and tomato seedlings. Plant Mol. Biol. 40:333-342.

Drolet, G., E. Dumbroff, R. Legge, and J. Thompson. 1986. Radical scavenging properties of polyamines. Phytochemistry 25:367-371.

Galston, A., R. Kaur-Sawhney, T. Altabella, and A. Tiburcio. 1997. Plant polyamines in reproductive activity and response to abiotic stress. Bot. Acta 110:197-207.

Grove, M., G. Spencer, W. Rohwedder, N. Mandava, J. Worley, J. Warthen, G. Steffens, J. Flippen-Anderson, and J. Cook. 1979. Brassinolide, a plant growth-promoting steroid isolated from Brassica napus pollen. Nature 281:216-217.

Houimli, S., M. Denden, and S. Hadj. 2008. Induction of salt tolerance in pepper (Capsicum annuum) by 24-epibrassinolide. EurAsian J. BioSciences 2:83-90.

Hwang, S. and T. VanToai. 1991. Abscisic acid induces anaerobiosis tolerance in corn. Plant Physiol. 97:593-597.

Kagale, S., U. Divi, J. Krochko, W. Keller, and P. Krishna. 2007. Brassinosteroid confers tolerance in Arabidopsis thaliana and Brassica napus to a range of abiotic stresses. Planta 225:353-364. 
Kang, Y., S. Guo, J. Duan, and X. Hu. 2006. Effects of 24-epibrassinolide on antioxidant system and anaerobic respiratory enzyme activities in cucumber roots under hypoxia stress. Agr. Sci. China 32:535-542.

Kim, T.H., M. Böhmer, H. Hu, N. Nishimura, and J.I. Schroeder. 2010. Guard cell signal transduction network: Advances in understanding abscisic acid, $\mathrm{CO}_{2}$, and $\mathrm{Ca}^{2+}$ signaling. Annu. Rev. Plant Biol. 61:561-591.

Krishnamurthy, R. 1991. Amelioration of salinity effect in salt tolerant rice (Oryza sativa L.) by foliar application of putrescine. Plant Cell Physiol. 32:699-703.

Li, H.S. 2000. Principles and techniques of plant physiological biochemical experiment. Higher Education Press, Beijing, China.

Li, W., M. Li, W. Zhang, R. Welti, and X. Wang. 2004. The plasma membranebound phospholipase $\mathrm{D} \delta$ enhances freezing tolerance in Arabidopsis thaliana. Nat. Biotechnol. 22:427-433.

Masidur, A., M. Hayat, S. Ali, and B.A. Ahmad. 2007. Effect of 28-homobrassinolide treatment on nickel toxicity in Brassica juncea. Photosynthetica 45:139-142.

Nakashita, H., M. Yasuda, T. Nitta, T. Asami, S. Fujioka, Y. Arai, K. Sekimata, S. Takatsuto, I. Yamaguchi, and S. Yoshida. 2003. Brassinosteroid functions in a broad range of disease resistance in tobacco and rice. Plant J. 33:887-898.

Nayyar, H. and S. Chander. 2004. Protective effects of polyamines against oxidative stress induced by water and cold stress in chickpea. J. Agron. Crop Sci. 190: 355-365.

Pospísilová, J. and P. Bat'ková. 2004. Effects of pre-treatments with abscisic acid and/or benzyladenine on gas exchange of french bean, sugar beet, and maize leaves during water stress and after rehydration. Biol. Plant. 48:395-399.

Rajasekaran, L.R. and T.J. Blake. 1999. New plant growth regulators protect photosynthesis and enhance growth under drought of jack pine seedlings. J. Plant Growth Regul. 18:175-181.

Ristic, Z. and E. Ashworth. 1993. Changes in leaf ultrastructure and carbohydrates in Arabidopsis thaliana L. (Heyn) cv. Columbia during rapid cold acclimation. Protoplasma 172:111-123.

Seki, M., T. Umezawa, K. Urano, and K. Shinozaki. 2007. Regulatory metabolic networks in drought stress responses. Curr. Opin. Plant Biol. 10:296-302.

Shen, W., K. Nada, and S. Tachibana. 2000. Involvement of polyamines in the chilling tolerance of cucumber cultivars. Plant Physiol. 124:431-440.

Uemura, M., R.A. Joseph, and P.L. Steponkus. 1995. Cold acclimation of Arabidopsis thaliana (effect on plasma membrane lipid composition and freezeinduced lesions). Plant Physiol. 109:15-30.

van de Dijk, S. and L. Smeets. 1984. Evaluation of physiological parameters for breeding for production under low temperature and light conditions. Proc. 10th Congr. European Assn. Res. Plant Breeding, p. 306 (abstr.).

Velikova, V.B., I.T. Yordanov, K.M. Georgieva, T.D. Tsonev, and V. Goltsev. 1998. Effects of exogenous polyamines applied separately and in combination with simulated acid rain on functional activity of photosynthetic apparatus. J. Plant Physiol. 153:299-307.

Vidya, V.B. and R.R.S. Seeta. 2003. Amelioration of osmotic stress by brassinosteroids on seed germination and seedling growth of three varieties of sorghum. J. Plant Growth Regul. 41:25-31.

Wang, L., L. Yang, F. Yang, X. Li, Y. Song, X. Wang, and X. Hu. 2010a. Involvements of $\mathrm{H}_{2} \mathrm{O}_{2}$ and metallothionein in NO-mediated tomato tolerance to copper toxicity. J. Plant Physiol. 167:12981306.

Wang, M., W.J. Jiang, and H.J. Yu. 2010 b. Effects of exogenous epibrassinolide on photosynthetic characteristics in tomato (Lycopersicon esculentum Mill) seedlings under weak light stress. J. Agr. Food Chem. 58:3642-3645.

Wang, Y.J., H.Y. Zhang, F. Zhang, Y. Xu, W.H. Cao, and G.B. Kang. 2001. Effects of low temperature and low light intensity stress on photosynthesis in seedlings of different cucumber varieties. Acta Hort. Sinica 28:230-234.

Xin, Z. and J. Browse. 2000. Cold comfort farm: The acclimation of plants to freezing temperatures. Plant Cell Environ. 23:893-902. 